\title{
Discourse, Syntax, and Prosody: The Brain Reveals an Immediate Interaction
}

\author{
Roel Kerkhofs ${ }^{1}$, Wietske Vonk ${ }^{1,2}$, Herbert Schriefers ${ }^{1}$, and \\ Dorothee J. Chwilla ${ }^{1}$
}

\begin{abstract}
Speech is structured into parts by syntactic and prosodic breaks. In locally syntactic ambiguous sentences, the detection of a syntactic break necessarily follows detection of a corresponding prosodic break, making an investigation of the immediate interplay of syntactic and prosodic information impossible when studying sentences in isolation. This problem can be solved, however, by embedding sentences in a discourse context that induces the expectation of either the presence or the
\end{abstract}

\section{INTRODUCTION}

The way a sentence is understood depends on the meaning of its words, its syntactic structure, its prosody, and the discourse in which it is embedded. Even in very simple sentences, syntactic word-order rules play a critical role: "John hit Jack" describes a different event from "Jack hit John." Furthermore, the prosody of a sentence can change its interpretation completely: A rising pitch on "John" in "Jack hit John" transforms the global interpretation from a statement to a question (Van Petten \& Bloom, 1999). However, in contrast to this sentence-level prosody, very little is known about how prosody interacts with syntax on a local level (cf. Cutler, Dahan, \& van Donselaar, 1997). In the present article, we focus on the question whether prosodic information is matched against syntactic information right at the point at which the critical prosodic information becomes available.

To address this question, we use locally ambiguous sentences that allow for two different syntactic analyses up to a certain point in the sentence after which the sentence becomes disambiguated by a lexical element. For example, in sentences such as (1) and (2) below, the sentences are ambiguous up to and including the noun phrase (NP) the policeman, and they are disambiguated at the word following this NP. In (1), the prepositional phrase (PP) on the square indicates that the coordinated

\footnotetext{
${ }^{1}$ Radboud University Nijmegen, ${ }^{2}$ Max Planck Institute for Psycholinguistics, Nijmegen, Netherlands
}

absence of a syntactic break right at a prosodic break. Eventrelated potentials (ERPs) were compared to acoustically identical sentences in these different contexts. We found in two experiments that the closure positive shift, an ERP component known to be elicited by prosodic breaks, was reduced in size when a prosodic break was aligned with a syntactic break. These results establish that the brain matches prosodic information against syntactic information immediately.

NP the squatter and the policeman is the object of the verb interviewed (NP-coordination), whereas in (2), the verb interrupted indicates that the policeman is the subject of a new sentence (sentence coordination; S-coordination). In (1), the squatter and the policeman form one constituent, in (2), there is a syntactic break between the squatter and and the policeman, the policeman being the first NP of the clause the policeman interrupted the interview right away.

(1) The reporter interviewed the squatter and the policeman on the square in front of the statue.

(2) The reporter interviewed the squatter and the policeman interrupted the interview right away.

In the present article, we study the processing of the Dutch equivalents of these locally ambiguous (henceforth called ambiguous) sentences. In written Dutch, these sentences can also be disambiguated at an earlier point, namely, at the squatter by means of a comma. In Dutch, it is not acceptable to place a comma in cases where two NPs are conjoined. Thus, a comma following the squatter disambiguates the sentence as an S-coordination. The Dutch language provides no strict rules regarding the placement of a comma in S-coordinated sentences (see Geerts, Haeseryn, de Rooij, \& van den Toorn, 1984). There is, however, a general habit of not putting commas before and in conjoined sentences (Renkema, 2004, pp. 163-164). Thus, the absence of a comma does not provide much useful information regarding the structure of a sentence, whereas its presence signals that an 
S-coordination (or a VP-coordination, for that matter) is very likely and excludes the possibility that the sentence will turn out to be a simple NP-coordination. For the auditory domain, one could hypothesize that a prosodic break after the squatter has the same disambiguating function as the comma in the visual domain.

Previous research in the visual domain using off-line and on-line measures - in particular, reading times and eye tracking - has shown that readers are initially inclined to interpret the ambiguous NP (the policeman) as part of the NP-coordination the squatter and the policeman (Hoeks, Hendriks, Vonk, Brown, \& Hagoort, 2005; Frazier, 1987). This is reflected in processing difficulty in S-coordinated sentences at or right after the disambiguating lexical element. Hoeks et al. (2005) compared temporarily ambiguous S-coordination sentences as in (3) with unambiguous S-coordinated control sentences as in (4) (literal English translation is given in italics). Note that the only difference between Sentences (3) and (4) concerns the presence or absence of a comma following farmer. The results of a self-paced reading experiment and an eye-movement experiment showed for sentences in isolation that reading times in the disambiguating region (defended) were longer in the absence of a comma after farmer (as in Sentence 3) than in the presence of a comma at this position (as in Sentence 4). Thus, in the absence of a comma, the sentence is initially analyzed as an NP-coordination. This initial analysis has to be revised when encountering defended. By contrast, when a comma is present, the sentence is right away (from the comma onwards) analyzed as an S-coordination, and thus, no processing difficulty occurs at the verb, as no reanalysis is necessary.

(3) De sheriff beschermde de boer en de knecht verdedigde dapper de ranch tegen Johnson's bende. The sheriff protected the farmer and the farm hand bravely defended the ranch against Johnson's gang.

(4) De sheriff beschermde de boer, en de knecht verdedigde dapper de ranch tegen Johnson's bende. The sheriff protected the farmer, and the farm hand bravely defended the ranch against Johnson's gang.

With respect to the potential impact of a prosodic break as an auditory analogue of a comma, the starting point for the present research was the discovery of an event-related potential (ERP) signature that is elicited by intonational phrase (IPh) boundaries, here referred to as prosodic breaks. Steinhauer, Alter, and Friederici (1999) demonstrated that prosodic breaks reliably elicit a positive shift, termed the closure positive shift (CPS), with a maximal centro-parietal distribution. Steinhauer (2003) has shown that the CPS is not attributable to the pause of the prosodic break alone. Sentences in which the pause was deleted still elicited a CPS. Thus, it appears that the CPS can be elicited by other ingredients of the prosodic break such as the boundary tone on the last syllable preceding the pause (Steinhauer, 2003).

Steinhauer and Friederici (2001) have found that a CPS is also elicited in delexicalized sentences (i.e., sentences with only the prosodic contour of spoken sentences but without any lexical and phonological content). In addition, Pannekamp, Toepel, Alter, Hahne, and Friederici (2005) reported that a CPS is elicited by a prosodic break in normal sentences, sentences without any semantic content (jabberwocky sentences), and in sentences without any semantic or syntactic content (pseudosentences). These results strongly suggest that the CPS is a prosodyinduced ERP component (see also Steinhauer, 2003 for further discussion).

A CPS-like component has also been observed in the area of music processing. Knoesche et al. (2005) presented listeners with musical phrases containing breaks while measuring their electroencephalogram (EEG) and magneto-encephalogram (MEG). The results showed a positive deflection around 500 to $600 \mathrm{msec}$ for EEG, and around 400 to $700 \mathrm{msec}$ for MEG. Source localization of the MEG signals showed that the effects originated from the anterior and posterior cingulates, areas that are also linked to memory and attention.

Earlier studies showed that prosodic information can be used to disambiguate lexical ambiguities and sentencelevel ambiguities. Salverda, Dahan, and McQueen (2003) showed that the length of a syllable can be used to discriminate between monosyllabic words (e.g., ham) and words that have the monosyllabic word as a first syllable (e.g., hamster). They performed a series of experiments in which they showed that the length of a syllable determined whether participants interpreted this syllable as a monosyllabic word, or as part of a larger word, irrespective of whether it originated from a monosyllabic word in isolation or an isolated first syllable of a larger word (see also Isel, Gunter, \& Friederici, 2003). Christophe, Peperkamp, Pallier, Block, and Mehler (2004) showed that a phonological boundary disambiguated continuity versus break ambiguities on the word level (e.g., in un chat grincheaux [a grumpy cat] the underlined part has the competitor chagrin [sorrow]). Shorter reaction times were measured in a word monitoring task and in a phoneme monitoring task when there was a phonological boundary present between chat and grincheaux, than when no such boundary was present, showing that the availability of prosodic information decreases the number of lexical candidates activated at any moment in time, resulting in faster and more efficient lexical access (see also Christophe, Gout, Peperkamp, \& Morgan, 2003).

There is also evidence that sentence-level prosody can interact with syntax. For instance, listeners can determine major syntactic breaks in delexicalized sentences or hummed sentences, based on prosody alone (e.g., Collier \& 't Hart, 1975; see Cutler et al., 1997 for an extensive review). More recently, Eckstein and Friederici 
(2005) performed a series of experiments on the prosody of sentence-final words. They found that if words with a sentence-final intonation are placed in a penultimate position, this mismatch between prosody and syntactic structure at the following word gave rise to an N400. They argued that the N400 on the final word reflects the increased costs to integrate this word into the context. When the final word of a sentence was marked as the penultimate word of a sentence, they reported a right anterior negativity, which was interpreted as a reflection of purely prosodic aspects of processing. As for the CPS, a parallel can be drawn with the ERP literature on music processing. Here an early right anterior negativity was reported (around $150 \mathrm{msec}$ ) following the violation of expectancies of the upcoming musical structure (See Koelsch, Gunter, Schröger, \& Friederici, 2003). Finally, Astésano, Besson, and Alter (2004) showed that a prosodic mismatch (e.g., a statement that ends with an F0 pattern typical for questions) can elicit a positive deflection that peaks around 800 msec after the onset of the prosodic pattern (P800). This P800 differs in three ways from the CPS. First, the CPS is functionally linked to the processing of prosodic boundaries, whereas the P800 is elicited by more sentence-level prosodic contours. Second, contrary to the CPS, the P800 is a narrow peak, and, third, is leftlateralized as opposed to the centro-parietal distribution of the CPS. In general, these studies on the processing of prosodic information suggest that prosody can play a disambiguating role on the word level and on the sentence level.

Prosody is also closely related to discourse structure as is evident from work on the relation between pitch accents and focus. For instance, Magne et al. (2005) presented participants with sentences that were embedded in contexts (questions) that set up expectations for particular focus structures. The prosodic structure of these sentences were either congruous or incongruous with these expectations. The ERPs showed different responses for congruous prosodic pitch contours and incongruous prosodic pitch contours. This shows that prosodic focus patterns are processed on-line by listeners to understand the pragmatic structure of a message.

The present article will study the processing of prosodic breaks in locally ambiguous sentences that are embedded in discourse contexts. The fact that a CPS is elicited by a prosodic break in itself does not show whether a prosodic break is being used in sentence comprehension. Therefore, Steinhauer et al. (1999) also tested whether a prosodic break could induce garden path effects. To this aim they constructed sentences in which the prosodic information and the syntactic information either were in line (both a prosodic break and a syntactic clause boundary were present at the same point in the sentence, or neither a prosodic break nor a syntactic clause boundary was present), or were in conflict with each other (a prosodic break was pres- ent, whereas there was no syntactic clause boundary). They confirmed that a CPS was elicited by the prosodic break. Furthermore, when the prosodic structure did not match the syntactic structure of the sentence, processing difficulty was observed at the point of the disambiguating syntactic information (which occurred in some words after the prosodic break), as reflected in a biphasic N400-P600 pattern. With respect to the functional significance of the CPS, Steinhauer and colleagues proposed that the CPS is tightly linked to the cognitive process of structuring the incoming speech signal: A CPS occurs immediately when a prosodic break is perceived and is used to guide syntactic parsing decisions. More specifically, the parser is assumed to postulate a syntactic break at the position of the prosodic break. If this postulated syntactic break is contradicted by lexicalsyntactic information at a later point in the sentence, processing difficulty will occur. The study by Steinhauer et al. shows that a prosodic break can lead to syntactic processing difficulty of several words after the occurrence of a prosodic break. However, these results do not provide an answer to the question whether prosodic information and syntactic information interact immediately when both types of information become available.

At first sight, the demonstration of this immediate interaction appears to be an impossible enterprise. Manipulating the presence versus absence of a syntactic break at the position of a prosodic break requires the use of locally syntactic ambiguous sentences that allow for syntactic analyses with and without a syntactic break up to at least the word following the prosodic break. However, this implies that the presence or absence of a syntactic break in such locally ambiguous sentences only becomes apparent in retrospect, at the point of syntactic disambiguation (the verb defended in Sentences 3 and 4), which necessarily follows the prosodic break. Consequently, the detection of a prosodic break and a syntactic break can never occur at the same point in the sentence.

We present a solution to this impasse by embedding locally ambiguous sentences in discourse contexts, which either induce an expectation of a syntactic break at the position of the prosodic break or do not induce such an expectation. If this context manipulation modulates the CPS to the identical spoken sentence, this would demonstrate that prosodic information is matched against the expected syntactic structure. Crucially, this context manipulation allows us to align the expectation of a syntactic break with the occurrence of a prosodic break at the same point in the spoken sentence. Only in this way is it possible to test whether the brain matches syntactic and prosodic information immediately when they become available.

To induce expectations about the syntactic structure, we made use of two principles of topic structure that have already been used by Hoeks, Vonk, and Schriefers (2002) in a visual study investigating context influences 
on the processing of the type of sentences used in the present study. Topic structure can be defined as describing the relation between the topic of a sentence (the element referring to an entity about which information is given) and the new information that is expressed in a sentence (Lambrecht, 1994). Furthermore, there is a strong tendency to have topics fulfill the syntactic function of subject of the sentence (Li \& Thompson, 1976).

The first principle is the principle of minimal topic structure: In the absence of explicit contextual or syntactic cues regarding the topic structure of a sentence, assume the simplest topic structure possible (Hoeks et al., 2002). That is, as a default, readers and listeners assume one topic in a sentence. According to Hoeks et al. (2002), the NP-coordination preference for sentences in isolation originates from the principle of minimal topic structure. NP-coordinations have one topic (i.e., the reporter in Sentence 1, which is the subject of the verb interviewed). By contrast, S-coordinations have two topics, one for each coordinated clause (i.e., the reporter and the policeman in Sentence 2, and the sheriff and the farm hand in Sentences 3 and 4), and thus, do not comply to the preferred minimal topic structure. The second principle is topic continuity (Givón, 1983). If a discourse entity has fulfilled the topic role in previous sentences in a discourse, or was introduced as a topic, there is a preference of having that entity in the topic role in a new sentence.

To induce the expectation of an S-coordination in sentences like (3) and (4), and thus, the expectation of a syntactic break between farmer and and, one can embed S-coordination sentences like (3) and (4) in a discourse (see Table 1) in which the sheriff and the farm hand is already introduced as one topic (see the biasing context Sentence B.2 in Table 1). After the listener has heard "The sheriff protected the farmer" in the target sentence (Sentence $\mathrm{C}$ from Table 1), the listener will conceive of the sheriff as a topic on its own. However, given the structure of the biasing context sentence, the farm hand wants to remain topic as well. The listener will therefore assume a syntactic structure of the target sentence that allows the farm hand to be topic (and thus to be in the subject position). The obvious way to accomplish this is to assume that after the farmer a new clause will start with the farm hand as the subject. This leads to the expectation of a syntactic break following farmer.

These contexts biasing toward an S-coordination (henceforth called biasing contexts) are contrasted with neutral contexts, which provide a general setting in which the critical sentence fits naturally, without mentioning any of the NPs of the coordination sentence (see the neutral context Sentence B.1 in Table 1). In the case of a neutral context, the minimal topic structure principle will apply, and therefore listeners assume only one topic, which is in line with an NP-coordination structure: The listener will not expect a syntactic break after the second NP (i.e., after farmer).
Table 1. Example of an Experimental Item Used in Experiments 1 and 2, with English Translation in Italics

A. Lead-in sentence

Nog geen dag nadat James "Mad Dog” Johnson werd vrijgelaten uit de gevangenis was het alweer raak in Painful Gulch.

Hardly a day since James "Mad Dog" Johnson's release from prison, trouble started again in Painful Gulch.

B.1. Neutral context ${ }^{\mathrm{a}}$

Toen Johnson zijn mannen weer opgetrommeld had, was de grootste boerderij in de buurt het doelwit van hun actie.

After Johnson summoned his men, the largest ranch in the neighborbood was targeted for their raid.

B.2. Biasing context ${ }^{\mathrm{a}}$

Toen ze de boer om hulp hoorden roepen, snelden de sheriff en de knecht naar de boerderij.

When they heard the farmer cry for help, the sheriff and the farm hand rushed to the ranch.

C. Target sentence

De sheriff beschermde de boer en de knecht verdedigde dapper de boerderij tegen Johnson's bende.

The sheriff protected the farmer and the farm hand bravely defended the ranch against Johnson's gang.

D. Exit sentence 1

$\mathrm{Na}$ een vuurgevecht van meer dan een uur kwam er eindelijk versterking voor de sheriff.

After a firefight of over an hour reinforcements for the sheriff finally arrived.

E. Exit sentence 2

Gelukkig kon Johnson nog dezelfde dag weer worden opgesloten.

Luckily Johnson was put behind bars again the very same day.

${ }^{a}$ In the experimental materials, either the neutral or the biasing context sentence was presented.

The effectiveness of this context manipulation has been established in reading time studies (Hoeks et al., 2002). In the Neutral Context condition, reading times on the disambiguating verb (e.g., defended) were longer in ambiguous S-coordination sentences such as (3) than in unambiguous S-coordination sentences such as (4), showing the default NP-coordination preference. This pattern of results changed when the sentences were embedded in a biasing context. In the Biasing Context condition, reading times for the disambiguating verb in the ambiguous (3) and unambiguous (4) S-coordinations did not differ. This shows that the biasing context successfully sets up a syntactic expectation of an S-coordination. Thus, reading the disambiguating verb in S-coordination 
sentences without a comma, but embedded in a biasing context, does not lead to processing difficulties. These results imply that, in the biasing contexts, readers indeed expected a syntactic break after the second NP (i.e., after farmer).

In the present experiments, we use this context manipulation to align a prosodic break between farmer and and with the expectation of a syntactic break at the same point. The experiment comprised four conditions. In the first two conditions, coordination sentences with a prosodic break were embedded in neutral and biasing contexts; in the other two conditions, coordination sentences without a prosodic break were embedded in neutral and biasing contexts. The syntactic disambiguation was always opposite to the prosodic information. That is, sentences that were disambiguated at the verb as S-coordinations did not have a prosodic break between farmer and and; sentences that were disambiguated at the PP as NP-coordinations did have a prosodic break between the second NP and and.

In order to demonstrate a direct match of prosodic and syntactic information, the sentences with a prosodic break in the Neutral Context condition were compared with the acoustically identical sentences in the Biasing Context condition. For the sentences with a prosodic break in the Biasing Context condition, the expectation of a syntactic break and the presence of a prosodic break coincide; in contrast, for the same sentences in the Neutral Context condition, the absence of the expectation of a syntactic break and the perceived prosodic break collide. Because the sentences within this critical comparison are the identical acoustic signals, any difference obtained at the prosodic break would demonstrate that prosodic information is immediately evaluated against the contextually induced syntactic expectation.

If prosodic information and syntactic information are matched immediately when they become available, we should see a reflection of this immediate matching in the CPS. Following the discussion above, we hypothesize that the deflection of the CPS is larger when a syntactic break is not expected at the position of the prosodic break (as in the Neutral Context condition), than when a syntactic break is expected at the position of the prosodic break. A modulation of the CPS by context would demonstrate that prosodic and syntactic information are matched immediately, that is, right at the point where the information becomes available.

\section{EXPERIMENT 1}

\section{Methods}

\section{Participants}

The participants were 30 undergraduate students (12 men and 18 women) from the University of Nijmegen. The participants were between 20 and 28 years of age, with a mean age of 23.1 years. All were right-handed; hand dominance was assessed by an abridged version of the Edinburgh Inventory (Oldfield, 1971). The participants were paid for their participation.

\section{Materials}

Before constructing the auditory stimulus materials, the materials that were used for the recording session were created in two steps. The point of departure was 60 S-coordination sentences (e.g., Sentence 4 repeated here as Sentence 5b) and 60 NP-coordination sentences (e.g., Sentence 1 repeated here as Sentence 6a) used in an earlier study. The S-coordination sentences are disambiguated by the second verb in the sentence (defended in 5b and interrupted in 6b). The NP-coordination sentences are, in principle, disambiguated at the end of the sentence. However, in the construction of the NPcoordination sentences, care was taken to choose PPs following NP3 that did not fit NP3 for continuation. For example, in (6a) it is unlikely that ... on the square is a PP modifying the NP the policeman, but rather provides the location of the entire scene. As a result, our NPcoordination sentences were disambiguated at the PP following NP3 (in front of the shed in 5a, and on the square in 6a).

For each of these sentences, a neutral context and a (S-coordination) biasing context were constructed. This resulted in $240(2 \times 2 \times 60)$ small stories of four to five sentences. A story consisted of a lead-in sentence, a context sentence, a target sentence, and one or two exit sentences (see Table 1).

In order to have the speaker produce the coordination part (the farmer and the farm hand) of each sentence both with and without a prosodic break, a second sentence was constructed with the opposite syntactic structure for each sentence. This was accomplished by modifying the NP-coordination sentences (6a) into S-coordination sentences by replacing the PP (on the square... in 6a) with a verb phrase (VP; interrupted ... in 6b). Likewise, the S-coordination sentences (5b) were modified into NP-coordination sentences by replacing the VP (defended ... in 5b) with a PP (in front of the shed... in 5a). This new PP (see the Dutch version in 5a) or VP (see the Dutch version in 6b) always started with the same phoneme as the old VP (as in 5b) or PP (as in 6a) to make later cross-splicing easier.

(5a) De sheriff beschermde [de boer en de knecht] voor de schuur waar een gevecht plaatsvond.

The sheriff protected [the farmer and the farm hand] in front of the shed where a fight was fought.

(5b) De sheriff beschermde [de boer en de knecht] verdedigde dapper de ranch tegen Johnson's bende. The sheriff protected [the farmer and the farm] hand bravely defended the ranch against Johnson's gang.

(6a) De journalist interviewde [de kraker en de agent] op de Dam voor het standbeeld. 
The reporter interviewed the squatter and the policemanj on the square in front of the statue.

(6b) De journalist interviewde [de kraker en de agent] onderbrak het interview meteen.

The reporter interviewed [the squatter and the policeman] interrupted the interview right away.

In sum, we had 60 S-coordination sets (consisting of the S-coordination sentence in a biasing and in a neutral context, plus the corresponding adapted-to-NPcoordination sentence) and 60 NP-coordination sets (consisting of the NP-coordination sentence in a biasing and in a neutral context, plus the corresponding adapted-to-S-coordination sentence). In addition to these experimental items, 6 starter items and 14 training items were created.

A female speaker recorded these materials. For each set, the speaker recorded the neutral context with its coordination sentence once, the biasing context with its coordination sentence once, and the adapted sentence twice. The speaker, a student of Dutch who was knowledgeable on Dutch prosody, was instructed to first read the sentences for herself, and then to read the sentences out loud. She was asked to produce a prosodic break after the second NP (NP2) in the S-coordination sentences, and to avoid a break after NP2 in the NPcoordination sentences. The materials were recorded in blocks of 10 sets in a row, alternating between 10 S-coordination sets and 10 NP-coordination sets. This resulted in $60 \mathrm{~S}$-coordination sentences with a prosodic break embedded in a neutral context, 60 S-coordination sentences with a prosodic break embedded in a biasing context, 60 NP-coordination sentences without a prosodic break embedded in a neutral context, 60 NP-coordination sentences without a prosodic break embedded in a biasing context, two times 60 modifiedto-NP-coordination sentences without a prosodic break, and finally, two times 60 modified-to-S-coordination sentences with a prosodic break.

From these recorded materials, the actual stimulus materials were constructed as follows. First, for each adapted sentence pair, the second sentence was discarded, except when the first had an artifact in it (e.g., a cough). Second, for each set, one target sentence was constructed by cross-splicing the segment between brackets from Sentence (5a) over the segment between brackets in Sentence (5b). The same cross-splicing was applied to (6b) and (6a). Note that the segments between brackets in (5a) and (5b) and in (6b) and (6a) are the same, except for their prosodic structure. This resulted in a target sentence in which the intonation was opposite to the syntactic disambiguation of the sentence. Third, half the neutral context tokens and half the biasing context tokens were duplicated, resulting in two identical tokens which were used as the basic frame to construct the final items. For each identical token pair, the cross-spliced target sentence was spliced in.
This resulted in 120 pairs (60 S-coordination and $60 \mathrm{NP}$ coordination pairs) of identical stories. Finally, the entire context sentence from the nonduplicated story was cross-spliced over the context sentence in one of the two copies. This resulted in stories in which the neutral and the biasing context only differed from each other with respect to the context sentences; the rest of the signal was acoustically identical. Therefore, any differences found between the two context conditions cannot be due to acoustic differences in the materials.

Table 2 shows the complete design of both Experiment 1 and Experiment 2. A full design with a complete crossing of the factors Context (neutral vs. biasing), Sentence Type (S-coordination vs. NP-coordination), and Prosodic Structure (prosodic break vs. no prosodic break) would have led to an experiment that would have been too long. As can be seen in Table 2, the S-coordination sentences in Experiment 1 do not have a prosodic break, whereas the NP-coordination sentences have a prosodic break. By contrast, in Experiment 2, the situation was reversed such that the S-coordination sentences had a prosodic break and the NP-coordination sentences did not. Within each experiment, the S-coordination sentences were acoustically identical across context conditions, as were the NPcoordination sentences. The sentences without a prosodic break in the biasing context condition were included as a filler condition to balance the possible combinations of context and prosodic structure so that the neutral context and the biasing context are followed by both a prosodic break and a no-prosodic break. ${ }^{1}$

The acoustic analyses of the target sentences showed clear differences between the Prosodic Break and the No-Prosodic Break conditions. Figure 1 shows examples of the typical prosodic break intonation and the typical continuation intonation. In the Prosodic Break condition (Figure 1, panel A), a pause between NP2 and and was present that lasted $321 \mathrm{msec}$ on average $(\mathrm{min}=$

Table 2. Design of the Experiments

\begin{tabular}{cccc}
\hline Experiment & Prosodic Break & Context & $\begin{array}{c}\text { Lexically } \\
\text { Disambiguated as }\end{array}$ \\
\hline Experiment 1 & Yes & Neutral & NP-coordination \\
& Yes & Biasing & NP-coordination \\
& No & Neutral & S-coordination \\
Experiment 2 & No $^{\text {a }}$ & Biasing & S-coordination \\
& Yes & Neutral & S-coordination \\
& Yes & Biasing & S-coordination \\
& No & Neutral & NP-coordination \\
& No $^{a}$ & Biasing $^{\text {a }}$ & NP-coordination \\
\hline
\end{tabular}

${ }^{\mathrm{a}}$ Condition was included as a filler condition (see text). 


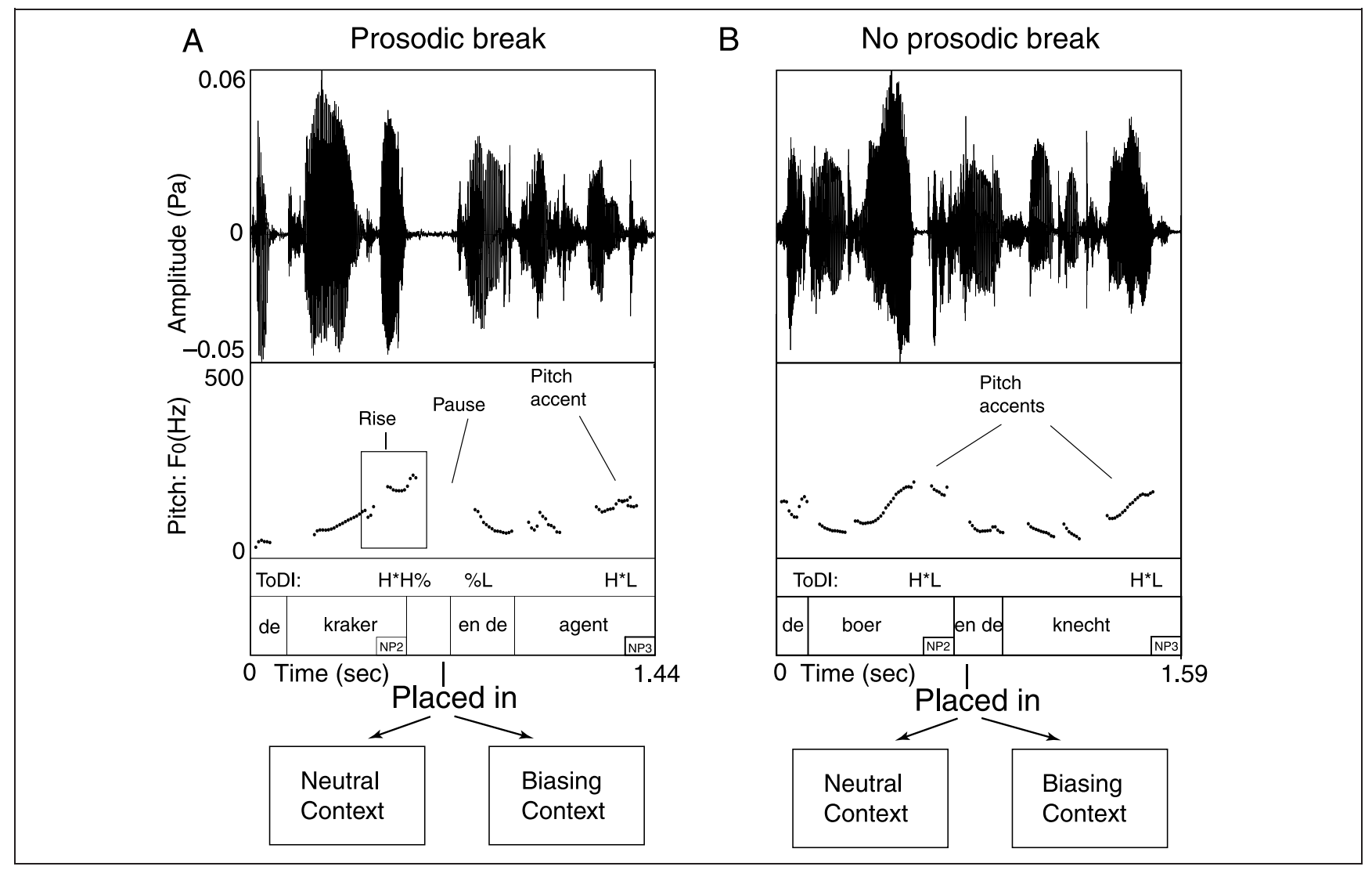

Figure 1. Acoustic properties of a typical critical region of the target sentence. The upper boxes show the amplitude of the speech signal in the Prosodic Break condition (panel A) and in the No-Prosodic Break condition (panel B). The middle boxes show the pitch-track of the speech signal in both conditions. The lower boxes show the transcription of the speech signal in ToDI (Gussenhoven, 2004) and in words.

99 msec, $\max =514$ msec, $S D=75.7 \mathrm{msec}$ ). Furthermore, a boundary tone was present on the last syllable of NP2 (i.e., on "...ker" from kraker in 6b). This boundary tone consisted of prefinal lengthening of the syllable combined with a pitch rise. The prosodic structure of the constructed target sentences was transcribed by two independent judges using the ToDI system (Gussenhoven, 2004; see ToDI line in Figure 1). The pattern from Figure 1 (panel A) consists of a pitch accent without a low target $\left(\mathrm{H}^{*}\right)$ followed by a high boundary tone $(\% \mathrm{H})$, a pause, a low boundary tone $(\% \mathrm{~L})$, and a pitch accent on the third noun $\left(\mathrm{H}^{*} \mathrm{~L}\right)$. This pattern occurred in $67 \%$ of the sentences with a prosodic break. In addition to this pattern, a pattern without a pitch rise in the boundary tone was observed in $23 \%$ of the sentences with a prosodic break (as denoted by the $\% 0$ in $\mathrm{H}^{*} \% 0 \% \mathrm{~L} \mathrm{H} \mathrm{L}$ ). Finally, in 10\% of the sentences with a prosodic break, a pattern was observed in which there was no low boundary tone following the prosodic break. In this pattern, the pitch of the utterance remained high on en de $\left(\mathrm{H}^{*} \% \mathrm{H} \% 0 \mathrm{H}^{*} \mathrm{~L}\right)$.

In the No-Prosodic Break condition (Figure 1, panel B), these features were not present. Instead, there were pitch accents on NP2 (farmer) and NP3 (i.e., the third NP: farm hand). The pattern from Figure 1 (panel B) was observed in $68 \%$ of the sentences without a pro- sodic break. In addition to this structure, instances in which the pitch accent on the first of the two NPs was lower than the pitch accent on the second NP occurred in $15 \%$ of the sentences without a prosodic break (as denoted by $! \mathrm{H}^{*} \mathrm{~L}$ in $! \mathrm{H}^{*} \mathrm{~L} \mathrm{H}^{*} \mathrm{~L}$ ). Finally, in $17 \%$ of the sentences without a prosodic break, the second pitch accent was smaller than the first pitch accent $\left(\mathrm{H}^{*} \mathrm{~L} ! \mathrm{H} * \mathrm{~L}\right)$. In summary, these transcriptions reveal clear differences between the two prosodic conditions: The prosodic break items all had a pause that was preceded by a boundary tone, the no-prosodic break items contained a pitch accent on each noun, but did not contain boundary tones or a pause.

\section{Design}

The 120 experimental items plus 6 starter items were divided into six blocks. Each block started with one starter item. Two lists were created pseudorandomly such that the maximum number of items from a given condition in a row was 3. Each list contained the items in the same order, but in different context conditions. Half of the participants listened to Version 1 and the other half listened to Version 2. The 14 training items were combined into a training block. Also for this block the list was generated in a pseudorandom fashion. 


\section{Apparatus}

The EEG was recorded from 25 tin electrodes mounted in an elastic electrode cap. The electrode positions were a subset of the international 10\% system, as used in earlier auditory ERP studies (e.g., Kerkhofs, Vonk, Schriefers, \& Chwilla, submitted). The left mastoid served as reference during the recording, but before the EEG was analyzed, the signal was re-referenced to software-linked mastoids. Electrode impedance was less than $3 \mathrm{k} \Omega$. Vertical electrooculogram (EOG) was recorded bipolarly by placing electrodes above and below the right eye. Horizontal EOG was recorded bipolarly by placing electrodes beside the left and beside the right eye. The electrode impedance of the EOG electrodes was less than $5 \mathrm{k} \Omega$. EEG and EOG channels were amplified (time constant = $10 \mathrm{sec}$, bandpass $=0.02-100 \mathrm{~Hz}$ ). All signals were digitized on-line with a sampling frequency of $500 \mathrm{~Hz}$ using a 16-bit A/D converter.

\section{Procedure}

The items were presented over headphones. A trial started with a warning beep of 100 msec. The auditory presentation of a sentence started $500 \mathrm{msec}$ after offset of the warning beep. The warning beep for the next trial followed $4000 \mathrm{msec}$ after the end of the preceding trial. Because eye movements distort the EEG signal, the participants were asked to look at a fixation point. They were trained to avoid eye blinks during the presentation of the items during a training block of 14 items that preceded the actual experiment. The participants were instructed to listen carefully to each story. They were not given any additional task.

\section{Results}

\section{Data Analysis}

The data were filtered with a low-pass filter of $30 \mathrm{~Hz}$. EEG and EOG records were examined for artifacts and for excessive EOG amplitude during the epoch from 150 msec preceding the offset of NP2 until 1000 msec after offset of NP2. Only trials in which the EOG did not exceed $75 \mu \mathrm{V}$, and in which no artifacts (EEG > $100 \mu \mathrm{V}$ ) occurred, were included in the analysis (11.08\% of the trials were excluded).

The window to quantify the CPS was the 400 to 800 msec epoch after NP2 offset. This window was based on visual inspection of the average waveforms and covers the latency window in which maximal differences between conditions were observed. Separate analyses were conducted for the midline and for the lateral sites. The midline multivariate analysis of variance (MANOVA) had the factors Prosodic Break (break/no break) and Midline Electrode $(\mathrm{Fz} / \mathrm{Cz} / \mathrm{Pz})$. The MANOVA for the lateral sites had Prosodic Break as factor, using a Hemisphere by
Region of Interest (ROI) by Electrode design. The factors Hemisphere and ROI divided the scalp into four quadrants: left anterior (AF7, F7, FC3, and F3), right anterior (AF8, F8, FC4, and F4), left posterior (CP5, P7, PO7, and $\mathrm{P} 3)$, and right posterior (CP6, $\mathrm{P} 8, \mathrm{PO} 8$, and $\mathrm{P} 4$ ).

The results will be presented in the following order. First, it was verified whether a standard CPS was obtained by comparing the prosodic break in the Neutral Context condition with the no prosodic break in the Neutral Context condition. Then it was tested whether the CPS was modulated by discourse context by comparing the identical target sentences with a prosodic break in the Neutral Context and in the Biasing Context conditions.

\section{Standard CPS}

Grand-average waveforms time-locked to the offset of NP2 for the Neutral Context, Prosodic Break condition and the Neutral Context, No-Prosodic Break condition are presented in Figure 2.

Figure 2 shows that the prosodic break gave rise to a CPS that was broadly distributed across the scalp. In line with this, the midline analysis for the window between 400 and 800 msec yielded a main effect of Prosodic Break $[F(1,29)=11.60 ; p<.01]$. No interaction of Prosodic Break by Midline Electrode was found $(F<1)$, indicating that the CPS was widely distributed across the midline. Likewise, the lateral analysis yielded a main effect of Prosodic Break $[F(1,29)=17.63 ; p<.001]$. In addition, a Prosodic Break by Electrode interaction $[F(3,27)=4.78$; $p<.01]$ and a three-way interaction between Prosodic Break, ROI, and Electrode $[F(3,27)=3.13 ; p<.05]$ were present. Separate analyses for the two levels of ROI showed effects of Prosodic Break for both the anterior ROI $[F(1,29)=19.17 ; p<.01]$ and for the posterior ROI $[F(1,29)=21.58 ; p<.001]$. The three-way interaction indicated that, at all individual sites except from two anterior sites (AF7/AF8), a significant CPS effect was obtained. The analyses thus support that the CPS showed a broad scalp distribution with effects being present at frontal, central, and posterior sites.

\section{Modulation of CPS by Context}

Grand-average waveforms time-locked to the offset of NP2 for the identical prosodic break in the Neutral and Biasing Context conditions are presented in Figure 3. Inspection of Figure 3 suggests that mean CPS amplitudes are more positive for the neutral context compared to the biasing context in the time window from 400 to $800 \mathrm{msec}$. This effect is present across the midline, but is most pronounced at centro-parietal midline sites (e.g., Cz, Pz). Furthermore, the effect seems to be present over the entire left hemisphere (e.g., FC3, CP5, and P3) and several sites over the right hemisphere (e.g., 




Figure 2. Standard CPS in Experiment 1. Grand-average waveforms over participants $(n=30)$, time-locked to the offset of NP2, for the No-Prosodic Break in Neutral Context condition (solid line) and the Prosodic Break in Neutral Context condition (dotted line).

P4 and CP6). Consistent with this, the midline analysis disclosed an effect of Context $[F(1,29)=4.68 ; p<.05]$, in the absence of a Context by Midline Electrode interaction $(F<1)$. Also, in the lateral analysis, a main effect of Context was found $[F(1,29)=7.25 ; p<.05]$. In addition, this analysis showed a Context by Hemisphere interaction $[F(1,29)=5.83 ; p<.05]$. Separate analyses for the two hemispheres showed a clear effect of Context for the left hemisphere $[F(1,29)=11.54 ; p<.001]$, but not for the right hemisphere $(p>$.090).

\section{Discussion}

The main results of Experiment 1 were as follows. First, the comparison of the Prosodic Break, Neutral Context condition with the No-Prosodic Break, Neutral Context condition gave rise to a standard CPS. Second, and most importantly, the CPS to acoustically identical tokens of sentences with a prosodic break was significantly smaller when these sentences were embedded in the Biasing Context condition than when they were embedded in the neutral context condition.

The onset latency of the CPS in the present study was somewhat later than those reported in previous studies (e.g., Steinhauer, 2003; Steinhauer et al., 1999). This difference in onsets is likely caused by important differences between the averaging and time-locking procedures that are used in the present study and in previous studies. In the present study, we use the default ERP methodology of time-locking each individual trial to a specific critical event and normalize the waveforms in a 150-msec interval directly preceding that event. The



Figure 3. Modulation by context in Experiment 1. Grand-average waveforms over participants $(n=30)$, time-locked to the offset of NP2, for the Prosodic Break in Neutral Context condition (dotted line) and the Prosodic Break in Biasing Context condition (solid line). 
critical event in our study is the offset of the second noun (and thus the onset of the pause in the condition with a prosodic break). Previous CPS studies (e.g., Steinhauer et al., 1999) time-locked and normalized the waveforms to the onset of the sentences, computing an average ERP waveform over the entire sentences. The location of a prosodic break in the auditory signal was then determined by computing the average location of the pause of the prosodic break in the auditory signal. The latency of the CPS is estimated by comparing the point in time at which the Prosodic Break condition and the No-Prosodic Break condition begin to differ, with the average position of the prosodic break. Clearly, this latter procedure has the disadvantage of "considerable latency variability across trials" (Steinhauer, 2003, p. 151), with respect to the onset of the pause of the prosodic break, a problem that does not occur when time-locking the ERPs to the offset of the word preceding the pause. On the other hand, the procedure used in the present study has the disadvantage that it does not take into account potential contributions of other acoustic aspects of the prosodic break that precede the pause, such as the prefinal lengthening and pitch rise of the boundary tone.

Taken together, it appears that the time windows in which a CPS is found in the present study and in previous studies cannot be compared directly due to these procedural differences in time-locking and averaging. It should be noted, however, that in the visual domain, the onset of the CPS in response to a comma (Steinhauer \& Friederici, 2001) shows a similar onset latency as the one observed in the present study. This makes perfect sense, as in the visual domain an analogue of our procedure was used: The ERP signals were time-locked to the specific critical event (the appearance of a word with or without comma attached to it).

In Experiment 1, the prosodic information always was in conflict to the syntactic disambiguation, which occurred several words after the prosodic break (i.e., the second verb in S-coordinations and the PP in NPcoordinations). One could argue that this aspect of the materials might have led our participants to pay specific attention to the prosodic structure of our materials. Given this consideration, it appears to be necessary to test whether the modulation of the CPS by context generalizes to a situation in which the presence or absence of a prosodic break is always in line with the syntactic disambiguation. Experiment 2 was conducted to clarify this issue.

\section{EXPERIMENT 2}

\section{Methods}

\section{Participants}

The participants were 30 undergraduate students with similar characteristics to those from Experiment 1, 4 men and 26 women, aged 19 to 25 years (mean age $=21.1$ years).

\section{Materials}

The same recordings as in Experiment 1 were used to create the materials. The first step was to select one coordination sentence for each item from the recorded pairs. For half of the S-coordination items and half of the NP-coordination items, this sentence originated from the biasing context, and for the other half from the neutral context.

In the second step, these target sentences were embedded in neutral and biasing contexts. Half of the neutral context tokens and half of the biasing context tokens were duplicated, resulting in two identical tokens, which were used as the basic frame to construct the final items. For each identical token pair, the target sentence that was selected in the first step was spliced in. This resulted in 120 pairs (60 S-coordination pairs and 60 NP-coordination pairs) of identical stories. Finally, the entire context sentence from the nonduplicated story was cross-spliced over the context sentence in one of the two copies. This resulted in 240 stories, in which the neutral and the biasing context only differed from each other with respect to the context sentence; the rest of the signal was acoustically identical.

In sum, the auditory stimulus materials consisted of 60 S-coordination sentences with a prosodic break in neutral and biasing context conditions and 60 NP-coordination sentences without a prosodic break in neutral and biasing context conditions.

\section{Design, Apparatus, and Procedure}

The design, apparatus, and procedure were identical to those of Experiment 1.

\section{Results}

\section{Data Analysis}

The data were preprocessed using the same procedure as in Experiment 1 (13.95\% of the trials were excluded because of artifacts). The same set of analyses as in Experiment 1 was carried out.

\section{Standard CPS}

Figure 4 shows grand-average waveforms time-locked to the offset of NP2 for the Prosodic Break condition and the No-Prosodic Break condition, both in neutral context. Inspection of Figure 4 suggests that a small CPS is present at the midline (see, for example, Fz and Cz) and at some sites of the right hemisphere (see, for example, FC4 and CP6). However, for the midline sites, no effect of Prosodic Break $(p>.25)$ or interaction between Prosodic Break and Midline Electrode $(F<1)$ was found. The lateral analysis did not disclose an effect of Prosodic Break $(p>.20)$, but did yield an interaction of Prosodic Break by Electrode by ROI $[F(3,27)=4.15 ; p<.05]$. 


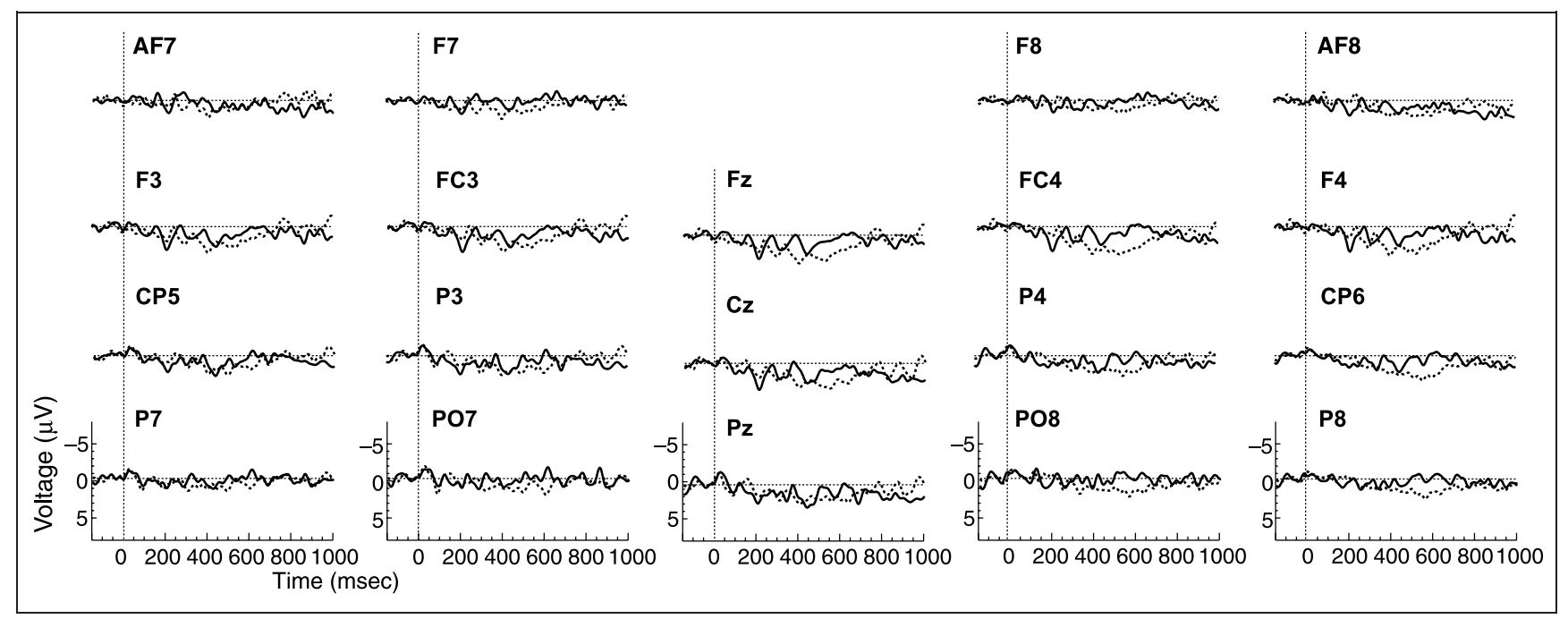

Figure 4. Standard CPS in Experiment 2. Grand-average waveforms over participants $(n=30)$, time-locked to the offset of NP2, for the No-Prosodic Break in Neutral Context condition (solid line) and the Prosodic Break in Neutral Context condition (dotted line).

Separate analyses for the two ROIs revealed an effect of Prosodic Break for the posterior ROI $[F(1,29)=5.01$; $p<.05]$, but not for the anterior ROI $(F<1)$. Supplementary analyses for the individual electrodes revealed a significant effect of Prosodic Break at three posterior sites over the right hemisphere: $\mathrm{CP} 6, \mathrm{P} 8$, and PO8 (all ps < .05). The CPS in Experiment 2 thus showed a centro-parietal scalp distribution that was restricted to the right hemisphere.

\section{Modulation of CPS by Context}

Grand-average waveforms time-locked to the offset of NP2 for the identical prosodic break in neutral and biasing contexts are presented in Figure 5. Inspection of Figure 5 suggests that overall differences between conditions are small. However, a small context effect seems to be present at the frontal midline site $(\mathrm{Fz})$, a subset of electrodes over the right hemisphere (FC4, CP6, PO8, and P8), and two electrodes of the left hemisphere (P7 and PO7). For the midline sites, no effect of Context $(p>13)$, and no interaction with Midline Electrode $(F<1)$ was found. For the lateral sites, no main effect of Context $(p>.25)$ was found, but the interaction of Context with ROI was significant $[F(1,29)=5.10 ; p<.05]$. Separate analyses for the two ROIs revealed an effect of Context for the posterior ROI $[F(1,29)=4.14 ; p<.05]$, but not for the anterior ROI $(F<1)$.

\section{Discussion}

As in Experiment 1, the comparison of the conditions with and without a prosodic break in neutral context yielded a standard CPS. The CPS occurred in the same

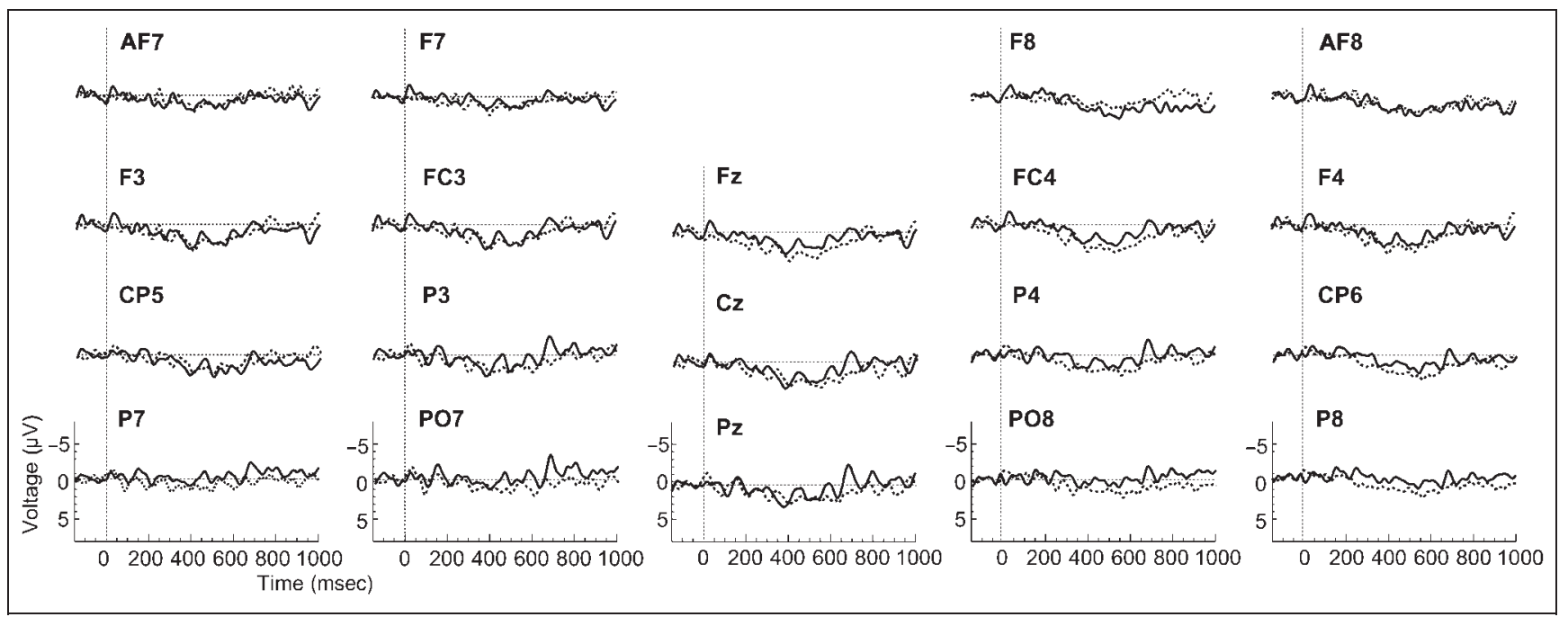

Figure 5. Modulation by context in Experiment 2. Grand-average waveforms over participants $(n=30)$, time-locked to the offset of NP2, for the Prosodic Break in Neutral Context condition (dotted line) and the Prosodic Break in Biasing Context condition (solid line). 
time window as in Experiment 1 (i.e., the $400-800$ msec epoch), but in contrast with Experiment 1, the CPS in Experiment 2 was restricted to the right hemisphere. More importantly, the CPS was smaller when the prosodic break was embedded in a biasing context, that is, when the prosodic break coincided with the expectation of a syntactic break, than when it was embedded in a neutral context.

To test whether the prosodic information and the syntactic disambiguation that were in conflict (Experiment 1) or in-line (Experiment 2) affected the ERPs, additional MANOVAs were performed with experiment (Experiment 1/Experiment 2) as an additional betweenparticipant factor. The MANOVAs testing for a standard CPS revealed clear effects of Prosodic Break both for the midline sites $[F(1,58)=10.49 ; p<.01]$ and for the lateral sites $[F(1,58)=15.72 ; p<.01]$. No interactions of Prosodic Break with the factor Experiment or other interactions of the factor Experiment with the factors Prosodic Break, Hemisphere, ROI, and/or Electrode were obtained neither for the midline nor for the lateral sites (all $p s>.10)$.

The MANOVAs testing for a modulation of the CPS by discourse context showed main effects of Context both for the midline sites $[F(1,58)=6.26 ; p<.05]$ and for the lateral sites $[F(1,58)=6.87 ; p<.05]$. No interactions between the factors Context and Experiment (both $p s>.25)$ or other interactions of these factors with Electrode, Hemisphere, or ROI were present (all $p$ s > .10). This indicates that the modulation of the CPS does not depend on whether the prosodic information is in line with the eventual disambiguation (as in the present experiment), or whether it is in conflict with the eventual disambiguation (as in Experiment 1).

\section{GENERAL DISCUSSION}

The main goal of our experiments was to shed light on the interaction of prosodic and syntactic information. More specifically, the aim was to test whether prosodic information and syntactic information interact immediately as they become available. In the literature, the effect of prosodic information on the processing of syntactically ambiguous sentences has only been shown several words after the critical prosodic information occurred. To test for the immediate interaction between prosodic and syntactic information, both kinds of information have to be aligned at the same point in the sentence. This alignment is impossible for sentences in isolation because the presence of a syntactic clause boundary only becomes apparent at the lexical element signaling the syntactic break (e.g., the disambiguating verb in S-coordinations), and this lexical element necessarily follows the syntactic break by one or more words. We provide a solution to this problem by embedding coordination sentences in contexts, which set up the expectation of a syntactic break at the position of a prosodic break, hereby aligning syntactic and prosodic information at the same point in the sentence.

The results from Experiment 1 and Experiment 2 showed a standard CPS. Most importantly, the present study shows a modulation of the CPS in acoustically identical sentences by contextually induced syntactic expectations. This is the case irrespective of whether the eventual lexical disambiguation was in conflict with the prosodic information (Experiment 1) or in line with the prosodic information (Experiment 2).

Up to now, we assumed that the positivity following NP2 is a CPS, which is elicited by the prosodic break. However, we have to keep in mind that, in the Neutral Context condition, a conflict occurs between prosodic information and syntactic information: By default, there is an expectancy of syntactic continuity (NP-coordination preference), but the prosodic break suggests a syntactic break. Could it be the case that the positivity reflects the violation of syntactic expectancies by prosodic information? If a prosodic break does induce a syntactic break, reanalysis of the syntactic structure might be required and a P600 might be elicited. Both the CPS and the P600 are positive shifts that peak around 500 to $600 \mathrm{msec}$ with similar scalp distributions. There is no easy way to discriminate between the two. However, related studies have shown that a CPS is also obtained at positions of a prosodic break that are not associated with any syntactic processing difficulties (e.g., Steinhauer, 2003). Furthermore, the CPS is also obtained in response to prosodic breaks in hummed sentences without any lexical context (e.g., Pannekamp et al., 2005; Steinhauer \& Friederici, 2001). Against the background of these studies, it appears highly likely that the positivity observed in the present study also constitutes a CPS. However, even if one would adopt a P600 interpretation, the observed modulation of the positivity by syntactic expectancy would still provide evidence for an immediate interaction of prosodic and syntactic information in auditory sentence processing.

A related point concerns the fact that the three NPs of the critical target sentences have already been mentioned before the target sentence in the Biasing Context condition, but not in the Neutral Context condition. At the word level, it has been shown that repeated words yield a biphasic ERP response-that is, an attenuation of the N400 component followed by an increase of a subsequent late positive component (LPC; Nagy \& Rugg, 1989). Also at the sentence level, ERP repetition effects have been reported. Besson and Kutas (1993) observed a context-dependent modulation of N400. In particular, they found a decrease in N400 amplitude only when repeated words occurred in the same context but not when repeated words occurred in different contexts. Furthermore, Anderson and Holcomb (2005) showed that N400 repetition effects can occur across a sentence boundary. Note that in the sentential studies repetition 
affected the N400 measured in the 300 to $600 \mathrm{msec}$ latency window but-opposite to studies at the word level-did not affect an LPC. The sensitivity of different ERP components to word repetition at the word and the sentence level (N400, and LPC) raises the question whether the modulation of the CPS by discourse context could be due to the repetition of the noun following the onset of the prosodic break (noun 3) in the Biasing Context condition. A closer look at the timing of the events in our study shows, however, that the context modulation of the CPS in our study cannot be due to repetition versus no repetition of the word following the prosodic break. The average length of the pause following NP2 was 321 msec. The average length of "en de" (and the) in the Prosodic Break condition was $174 \mathrm{msec}$ $(S D=37 \mathrm{msec})$. Thus, the onset of the third noun occurs $495 \mathrm{msec}$ after the onset of the pause. However, the modulation of the CPS already started at $400 \mathrm{msec}$ following the onset of the pause, that is, on average, 95 msec before the onset of the third noun. This makes it impossible that the modulation is caused by the repetition of this third noun.

Up to now, we have shown that the presence of a prosodic break is matched immediately against the expectation of a syntactic break by comparing identical tokens of sentences with a prosodic break in two context conditions (Neutral vs. Biasing Context). But is the presence of a prosodic break alone sufficient to disambiguate the sentence towards an S-coordination, or is complete early disambiguation only possible if the prosodic break coincides with the syntactic expectation of a break? To answer this question, we contrasted the waveforms at the disambiguating verb in S-coordination sentences with a prosodic break in neutral contexts and in biasing contexts. If the prosodic break alone is sufficient for early disambiguation, the waveforms at the disambiguating verb should not show a difference between the neutral and the biasing contexts. If a prosodic break only leads to an early disambiguation when also a syntactic break is expected at this point in the sentence, the sentences in biasing context should be disambiguated at the prosodic break, whereas the sentences in neutral context should remain ambiguous up to the disambiguating verb. This should lead to processing difficulty at the disambiguating verb in the Neutral Context condition relative to the Biasing Context condition. The results at the disambiguating verb showed no differences between the neutral and biasing contexts, indicating that the prosodic break alone was sufficient to disambiguate the sentences as S-coordinations. This is in line with the findings of Steinhauer et al. (1999), who have shown that a prosodic break can induce garden paths in isolated sentences.

The main findings of the present study can be summarized as follows: First, we replicated a CPS in response to the occurrence of a prosodic break as compared to sentences without a prosodic break. Second, and cru- cially, using a discourse context manipulation, we have demonstrated that the CPS elicited by an acoustically identical prosodic break is modulated as a function of a contextually induced syntactic expectation. When the prosodic break coincided with a syntactic break, the CPS was significantly smaller than when the prosodic break did not coincide with a syntactic break. This result shows that syntactic information and prosodic information interact, and crucially, that they interact immediately at the point at which the prosodic information becomes available.

The picture that emerges from the available literature is that prosodic information is able to guide the parser, and helps to predict upcoming materials. To date, little information on the time course of this process is available. Based on the present data, we cannot tell whether prosodic information is primary and driving the syntactic analysis, or whether syntactic information is primary and prosodic information is used to confirm the syntactic structure. What the present results do reveal, however, is that both sources of information are matched immediately as they become available. That is, there is no delay in the usage of prosodic information. This immediate interaction of prosody and syntax only becomes evident when studying the processing of sentences in a discourse context instead of focusing on the processing of isolated sentences.

Reprint requests should be sent to Wietske Vonk, P.O. Box 310 , NL-6500 AH Nijmegen, the Netherlands, or via e-mail: vonk@ mpi.nl.

\section{Note}

1. This condition also allowed us a first exploration whether the absence of a prosodic break is a prosodic cue that can interact with syntactic expectations. Although some subtle differences were found between the no-prosodic break conditions in neutral context and in biasing context, the results were inconclusive. Therefore, the results are not reported in the present article.

\section{REFERENCES}

Anderson, J. E., \& Holcomb, P. J. (2005). An electrophysiological investigation of the effects of coreference on word repetition and synonymy. Brain and Language, 94, 200-216.

Astésano, C., Besson, M., \& Alter, K. (2004). Brain potentials during semantic and prosodic processing in French. Cognitive Brain Research, 18, 172-184.

Besson, M., \& Kutas, M. (1993). The many facets of repetition: A cued recall and event-related potential analysis of repeating words in same versus different sentence contexts. Journal of Experimental Psychology: Learning, Memory, and Cognition, 19, 1115-1133.

Christophe, A., Gout, A., Peperkamp, S., \& Morgan, J. (2003). Discovering words in a continuous speech stream: The role of prosody. Journal of Phonetics, 31, 585-598. 
Christophe, A., Peperkamp, S., Pallier, C., Block, E., \& Mehler, J. (2004). Phonological phrase boundaries constrain lexical access: I. Adult data. Journal of Memory and Language, 51, 523-547.

Collier, J., \& 't Hart, R. (1975). The role of intonation in speech perception. In A. Cohen \& S. G. Nooteboom (Eds.), Structure and process in speech perception (pp. 107-121). Heidelberg: Springer-Verlag.

Cutler, A., Dahan, D., \& Van Donselaar, W. (1997). Prosody in the comprehension of spoken language: A literature review. Language and Speech, 40, 141-201.

Eckstein, K., \& Friederici, A. D. (2005). Late interaction of syntactic and prosodic processes in sentence comprehension as revealed by ERPs. Cognitive Brain Research, 25, 130-143.

Frazier, L. (1987). Syntactic processing: Evidence from Dutch. Natural Language and Linguistic Theory, 5, 519-559.

Geerts, G., Haeseryn, W., de Rooij, J., \& Van den Toorn, M. C. (1984). Algemene Nederlandse spraakkunst [General grammar and usage of Dutch]. Groningen: Wolters-Noordhof.

Givón, T. (1983). Topic continuity in discourse: A quantitive cross-language study. In T. Givón (Ed.), Topic continuity in discourse: An introduction (pp. 1-42). Amsterdam: Benjamins.

Gussenhoven, C. (2004). Transcription of Dutch intonation. In S. Jun (Ed.), Prosodic typology and transcription: A unified approach. Oxford: Oxford University Press.

Hoeks, J. C. J., Hendriks, P., Vonk, W., Brown, C. M., \& Hagoort, P. (2005). Processing the noun phrase versus subject coordination ambiguity: Thematic information does not completely eliminate processing difficulty. Quarterly Journal of Experimental Psychology, 59, 1581-1599.

Hoeks, J. C. J., Vonk, W., \& Schriefers, H. (2002). Processing coordinated structures in context: The effect of topic-structure on ambiguity resolution. Journal of Memory and Language, 46, 99-119.

Isel, F., Gunter, T. C., \& Friederici, A. F. (2003). Prosody-assisted head-driven access to spoken German compounds. Journal of Experimental Psychology: Learning, Memory, and Cognition, 29, 277-288.

Kerkhofs, R., Vonk, W., Schriefers, H., \& Chwilla, P. J. (submitted). Sentence processing in the visual and auditory modality: Do comma and prosodic break have parallel functions?

Knoesche, T. R., Neuhaus, C., Haueisen, J., Alter, K., Maess, B., Witte, O. W., et al. (2005). Perception of phrase structure in music. Human Brain Mapping, 24, 259-273.

Koelsch, S., Gunter, T. C., Schröger, E., \& Friederici, A. D. (2003). Processing tonal modulations: An ERP study. Journal of Cognitive Neuroscience, 15, 1149-1159.

Lambrecht, K. (1994). Information structure and sentence form: Topic, focus, and the mental representation of discourse referents. Cambridge: University Press.

Li, C. N., \& Thompson, S. A. (1976). Subject and topic. In C. N. Li (Ed.), Subject and topic: A new typology of language (pp. 457-490). New York: Academic Press.

Magne, C., Astésano, C., Lacheret-Dujour, C., Morel, M., Alter, K., \& Besson, M. (2005). Online processing of "pop-out" words in spoken French dialogues. Journal of Cognitive Neuroscience, 17, 740-756.

Nagy, M. E., \& Rugg, M. D. (1989). Modulation of event-related potentials by word repetition: The effects of inter-item lag. Psychophysiology, 26, 31-36.

Oldfield, R. C. (1971). The assessment and analysis of handedness: Edinburgh inventory. Neuropsychologia, 9, 97-113.

Pannekamp, A., Toepel, U., Alter, K., Hahne, A., \& Friederici, A. D. (2005). Prosody-driven sentence processing: An event-related brain potential study. Journal of Cognitive Neuroscience, 17, 407-421.

Renkema, J. (2004). Schrijfwijzer. Den Haag: SDU.

Salverda, A. P., Dahan, D., \& McQueen, J. M. (2003). The role of prosodic boundaries in the resolution of lexical embedding in speech comprehension. Cognition, 90, 51-89.

Steinhauer, K. (2003). Electrophysiological correlates of prosody and punctuation. Brain and Language, 86, $142-164$.

Steinhauer, K., Alter, K., \& Friederici, A. D. (1999). Brain potentials indicate immediate use of prosodic cues in natural speech processing. Nature Neuroscience, 2, 191-196.

Steinhauer, K., \& Friederici, A. D. (2001). Prosodic boundaries, comma rules, and brain responses: The closure positive shift in ERPs as a universal marker for prosodic phrasing in listeners and readers. Journal of Psycholinguistic Research, 30, 267-295.

Van Petten, C., \& Bloom, P. (1999). Speech boundaries, syntax and the brain. Nature Neuroscience, 2, 103-104. 